\title{
OLD-AGE PROVISION: PAST, PRESENT, FUTURE
}

\author{
Hansjörg Albrecher, Paul Embrechts, Damir Filipović, Glenn Harrison, Pablo Koch, \\ Stéphane Loisel, Paolo Vanini, Joël Wagner
}

\begin{abstract}
This is a summary of the main topics and findings from the Swiss Risk and Insurance Forum 2015. That event gathered experts from academia, insurance industry, regulatory bodies, and consulting companies to discuss the past and current developments and necessary next steps for dealing with oldage provision. Topics include the pension funding gap, demographic and societal challenges, the valuation of pension liabilities, economic and regulatory capital models, and the role of financial markets.
\end{abstract}

\section{EXTENDED ABSTRACT}

This is a summary of the main topics and findings from the Swiss Risk and Insurance Forum 2015. That event gathered experts from academia, insurance industry, regulatory bodies, and consulting companies to discuss the past and current developments and necessary next steps for dealing with old-age provision. The following five topics are identified as important directions for future research and policy implications:

1. Funding gap: adequate choice of pension system and communication, definition of contribution and benefits, inter- and intra-generational transfers, need for an independent body like a pension stability board to advice the government.

2. Demographic and societal challenges: longevity and migration, generational fairness and transparency, as well as their integration in actuarial approaches.

3. Valuation of pension liabilities: market consistency reloaded and challenged, demandversus supply-sided view, choice of discount curve.

4. Economic and regulatory capital models: long-term versus short-term view, cash flow solvency versus balance sheet solvency, level of reserves, remediation mechanisms, communication.

5. Role of financial markets: structuring financial long-term guarantees, potential of and limits to insurance risk transfers, new generations of innovative products taking societal changes at all levels into account. 


\section{Introduction}

One of the most serious challenges for society today is the financing of the pension system. Demographic trends and the changed reality in financial markets have rendered traditional models for securing the financial situation of retired people inadequate. In advanced economies, the baby boom generation is starting to reach retirement age and the ratio of the number of people of working age to the number of retirees is continuously decreasing. In addition to issues for health and social care, this trend poses a serious challenge for pay-asyou-go systems. On the political level, several measures are in the process of being adopted ranging from the raising of retirement age to a greater reliance on private pension plans. An aggravating factor has been a prolonged period of low interest rates and the financial crisis which amongst its many dire consequences significantly depleted the value of pension funds' assets.

In order to generate practical and methodological impulses for necessary financial and actuarial approaches to address these problems, the Swiss Risk and Insurance Forum organized a conference on the topic of "Old-age provision: past, present, future", which took place on November 16-17, 2015 at the Swiss Re Centre for Global Dialogue, Rüschlikon. The conference gathered 36 international experts from academia, insurance industry, regulatory bodies and consulting companies to reflect about this topic. This document summarizes some of the issues raised in these discussions and outlines some of the suggested next steps that have been identified as important for dealing with the corresponding challenges. This document is not meant to reflect a consensus opinion and the ultimate choice of topics and emphasis is purely that of the authors.

Section 2 first gives a brief overview of existing pension systems and by way of example discusses the case of Switzerland in some more detail. The customer's perspective on pension systems is also included. Section 3 deals with the demographic development, actuarial considerations of the latter and discusses some effects of societal changes on old-age provision. Section 4 reviews some issues related to risk management, particularly challenges with the notion of market consistency, valuation and the definition of risk measures in general. Section 5 identifies some of the most important challenges with respect to the role of financial markets for old-age provision and the potential of risk transfer.

\section{Retirement provision systems}

\subsection{Provision systems and "best practice"}

The two main objectives of pension systems are to reduce or eliminate poverty at old age and to ensure that people save during their working life to finance their retirement. As a part of a state's safety net, maintaining adequate levels of income at old age goes along with redistribution of wealth between generations and within cohorts. The pension programs in current retirement provision systems differ in various aspects. The plans can be mandatory or voluntary, managed through public or private institutions, and can be linked to an employer or not (occupational pension plan or personal plan). With regard to financing of the benefits one distinguishes between pay-as-you go (PAYG) programs, where the benefits are financed with current contributions, and funded programs, where assets are accumulated. The 
relationship between the contributions into the plan and the pension payments out of the plan is crucial. Pension benefits can be defined ex-ante (defined benefit plans, DB) or alternatively out-payments depend on the amount of assets accumulated at retirement (defined contribution plans, DC). The latter variant often includes some type of guarantees on the assets, like, for example, a minimum return guarantee. Depending on the structure of the pension program, the risk exposure (biometric, capital market, systemic risk, etc.) is different and can be borne by the employer (e.g., in the case of employer-sponsored DB plans), the pension providers (e.g., return guarantees given on accumulated assets), the tax-payers (e.g., PAYG public pensions) or the individual (e.g., pure DC plans). The following table gives an overview of differentiation criteria of pension programs (cf. also OECD, Glossary of Statistical Terms).

\begin{tabular}{|l|l|}
\hline Compulsory? & $\begin{array}{l}\text { - Mandatory: obligation by law to participate in a program } \\
\text { - Voluntary: no obligation to participate (e.g. personal plans) }\end{array}$ \\
\hline $\begin{array}{l}\text { Management of the } \\
\text { program }\end{array}$ & $\begin{array}{l}\text { - Public: administered by the general government (state, } \\
\text { public sector bodies) } \\
\text { - Private: administered by a private sector employer, private } \\
\text { fund or private sector provider }\end{array}$ \\
\hline $\begin{array}{l}\text { Existence of an } \\
\text { employment relationship }\end{array}$ & $\begin{array}{l}\text { - Occupational: the access point is through the employer } \\
\text { (e.g. employer-sponsored plans) }\end{array}$ \\
\hline Fersonal: through employer (with minimal role) or no \\
employment
\end{tabular}

All old-age provision systems use a combination of the above described types of programs. In different countries, the weight of each of the components in the overall retirement income varies. The following criteria may be used to assess the practicability of a system and to possibly define "best practice" (see also the pension indicators in OECD, 2016):

1. Replacement rate: What is the level of retirement income in comparison to the revenue during the employment phase?

2. Coverage rate: Which share of the population is covered by the system, considering both mandatory and voluntary plans?

3. Fiscal and financial sustainability: Are the different programs in the system viable in the long run?

4. Level of contribution: What is the contribution-to-revenue-ratio during the active employment phase and how does the level change with age?

5. Risk bearing: Who is bearing what type of risks; in particular, which risks are borne by individuals? 
Most public programs yield high coverage and replacement rates with little to no risk left for individuals in PAYG programs, but they are rather expensive and their fiscal sustainability must be questioned in times of adverse demographic developments. Currently the systems implemented in Denmark and the Netherlands are considered among the most resilient systems, ${ }^{1}$ providing high replacement rates, good coordination between public and private provision and leaving low risk to individuals. However, this comes at the price of relatively high contributions. In both countries the pension programs face funding and fiscal sustainability issues linked to an assets and liabilities mismatch (Dutch system) and fiscal challenges (Denmark).

Defined contribution plans, on the other hand, are sustainable by construction but leave higher risk to individuals. Due to flaws in the design like low contribution rates, they deliver only low retirement income (see OECD, 2012). Current trends go into the direction of increasing the role of private pensions financing the retirement and a shift from defined benefits to defined contributions schemes (OECD, 2014). In fact, the impact of ageing, i.e. improvements in life expectancy (see Section 3), depends on the set-up of the pension program. If individuals spend more years in retirement than in the period saving for retirement, this inevitably leads to solvency problems for defined benefits pensions.

We have seen that, in general, different types of pension plans will coexist within the same jurisdiction. Since each of these calls for a different regulatory approach, pension plans are not addressed by a single regulation.

\subsection{The example of Switzerland}

For the purpose of illustration, we briefly outline here the old-age provision system in Switzerland. From a conceptual point of view, the Swiss system has a balanced structure relying on three pillars. The first pillar is a PAYG program that is compulsory for everybody and aims to cover the basic subsistence needs. The second pillar is a funded occupational program compulsory for all employees. Together with the first pillar, its goal is to allow the pensioner to maintain the standard of living. Finally, private savings are encouraged in a tax-privileged third pillar. Recognized factors that influence the system are the decrease of the birth rate, the increase of life expectancy, immigration (see also the discussion in Section 3 ) and the low level of interest rates in recent years (see Sections 4 and 5).

In its present implementation, the contributions and payments account for approximately $6 \%$ of the GDP in the first pillar. The PAYG system in place has been in equilibrium for a long time, mainly due to immigration. In the future, the system is expected to deteriorate progressively (character of a Ponzi scheme). ${ }^{2}$ In the second pillar, the individually funded accounts lay a solid basis for old-age benefits. Overall, the aggregated contributions amount to $10 \%$ of the GDP while total payments are only in the range of $7 \%$ today. However, the pension payments are calculated for the sum of all contributions at retirement age using a conversion rate of $6.8 \%$

\footnotetext{
${ }^{1}$ See, e.g., a comparison based on the 2015 Melbourne Mercer Global Pension Index. ${ }^{2}$ Depending on the valuation methods (discounting future contributions and payment basis), the system already today has a deficit of about 1.75 times the GDP (see Moog et al., 2014).
} 
p.a. ${ }^{3}$ Given today's life expectancy and the level of interest rates, the economically correct conversion rate would amount to much less. ${ }^{4}$ As a consequence, the average new pension in the compulsory part is currently much too high, so that - contrary to the initial idea - a large PAYG element appears in the second pillar, because too high pensions today are financed from current contributions.

Under the header "Provision for Old Age 2020" the Swiss government has proposed a number of measures in order to correct the situation. The two main measures are the raising of the retirement age of women from 64 to 65 and the lowering of the conversion rate in the compulsory part of the second pillar from $6.8 \%$ to $6.0 \%$ p.a. These propositions are, however, far from sufficient to improve the sustainability of future financial cash flows. In fact, it seems that the government does not want to confront the general public with the uncomfortable "truth" about the situation (see Section 4 for valuation, solvency measurement and communication).

\subsection{The general public and customer perspectives}

During their active life, especially at lower ages, people are less concerned with retirement provision. There are at least three known reasons for this. First, an overall rather low financial literacy in the population is a handicap for grasping the different facets of the problem and for making improvements to the financial behavior (see, e.g., Lynch et al., 2010). Second, consumers seem to be reluctant to get involved in pension issues. A lack of engagement in the choice of products, in the question on the amount to save and in the asset allocation can be observed. Here a more personalized communication by pension providers may increase the commitment. ${ }^{5}$ In the last years a trend that customers want more choice has been observed (see also the societal changes discussed in Section 3). However, dealing with choice is a challenge for many, especially when pension plans and insurance contracts with guarantees and options are concerned. In this context, the "annuity puzzle" and the reasons for people to purchase income annuities (i.e.. exchange a lump sum payment for a guaranteed lifetime income stream) need to be understood. Third, customers differ with respect to age, risk aversion, and their propensity to plan and to save. Some individuals experience anxiety ahead of retirement while others look forward to it. The specific needs of each segment are to be identified and addressed (Brüggen et al., 2015).

Given the critical situation and difficult reforms that are necessary in many countries' old-age provision systems, an adequate communication strategy is needed. Accurate information needs to be communicated in a way that is easy to understand. Assessing the funding gap and truly informing the public is often difficult given the number of assumptions underlying the scenario calculations and the valuation perspectives taken at the system level (cf. Sections 3 and 4). Also, confronting the public or the individual with the full extent of the systemic

\footnotetext{
${ }^{3}$ This is a minimum rate to be applied on the compulsory part of the contributions (i.e., on the salary part up to CHF 84 '600 in 2015). For the optional part, mostly substantially lower rates apply in practice.

${ }^{4}$ The current economically fair conversion rate is considered to be below $4 \%$ p.a.

${ }^{5}$ See for example the initiative "Proberentnern" by Swiss Life, https://www.swisslife.ch/de/home/dialog/blog/2016/01/ proberentnern -sw.html.
} 
funding gap is politically unpleasant and may lead to paralysis. In order to facilitate the public information and decision process, an output-focused (and possibly risk-based) communication approach outlining the consequences at the individual level should be taken in order to increase the commitment of the general public in this difficult matter.

\section{Demographic and societal changes}

\subsection{Demographic developments}

Most developed countries have been experiencing longevity improvements during the last decades. This evolution has bred what is often called "longevity risk". This increase of longevity is probably one of the greatest universal achievements of mankind (so the terminology "risk" may not be fortunate). It has changed expectations of citizens and customers: they aspire to a longer, financially secure lifetime in good health, but also to a meaningful life. This has also influenced their labor market participation, and created multiple challenges and opportunities related to the so-called silver economy.

Longevity patterns and improvement trends are complex. According to detailed studies by demographers (see e.g. Cutler et al., 2006), many explanatory variables are relevant for the random lifetime at the individual (or micro-) level, including age, gender, education level, lifestyle including smoking and drinking habits, wealth and marital status. One should note that these explanatory variables are far from independent of each other. Affluence is one of the appropriate variables to consider for longevity studies with individual characteristics (also called traits). Educational level is also considered a decisive criterion for longevity modeling (see e.g. Lutz and Samir, 2011).

Recent studies in the US ${ }^{6}$ show that longevity differences between people with low level education and people with higher education are widening or are at least not narrowing. A methodological challenge in such a study is the fact that the proportion of people with low education decreases over time; some demographers therefore use quantiles of education level rather than absolute education levels. Similar challenges appear in the study of other key variables like marital status: married men and women live on average longer than unmarried individuals of the same gender, partly due to the assistance of their spouse. Between ages 60 and 80 , men benefit, however, much more from marriage than women, as they have a higher probability to receive that assistance from their spouse when needed: their wives are less likely to die earlier and consequently more likely to be there to assist them.

\subsection{Actuarial considerations}

To understand and model longevity at the population level (macro level), one needs to take into account the forces at the individual level. However, in classical actuarial approaches (cf. Lee and Carter, 1992, Cairns et al., 2006), one studies mortality rates per age class and gender as time series or stochastic processes. In countries like in the UK, one often includes a socalled cohort effect: individuals born in some years seem to experience lower mortality rates

\footnotetext{
${ }^{6}$ See the book The Growing Gap in Life Expectancy by Income: Implications for Federal Programs and Policy Responses available from http://www.nap.edu/19015.
} 
and higher longevity improvement rates than the ones born in neighboring years (see e.g. Renshaw and Haberman, 2006). It has recently become apparent that a great part of this cohort effect can actually be explained by the impact of irregular birth patterns in periods of trouble (as Cairns et al., 2016, write, "phantoms never die").

More generally, nonlinearities make it necessary to study not only mortality rates, but also the dynamics of the entire population as well as the traits of its individuals. To take this into account, researchers so far have mainly focused on multi-state models (to account for long term care insurance risks) and multi-population models. Studies on two-population models are motivated both by forecasting problems for small populations and by risk management issues. For example, to build market prospective mortality tables for the French life insurance market in 2005-2006, actuaries were able to compile 19 insurance portfolios corresponding to 700,000 individuals. However, even in this case it was impossible to build prospective life tables without reference to a larger population, namely the national French population. Several recent studies (Lazar and Denuit, 2009, Salhi and Loisel, 2011, Ntamjokouen et al., 2014) tackle forecasting issues and test for cointegration between mortality-related time series of different populations. Another motivation for studying in detail the link between individual and collective mortality patterns comes from basis risk management. Typically investors are more comfortable with standardized longevity swaps, the cash-flows of which are based on national population mortality evolution. One reason is that such products are less prone to asymmetry of information than customized longevity swaps (the cash-flows of which are based on the mortality of a particular group, typically the members of a pension fund or the customers of a life insurance company). But then, insurance and pension fund risk managers face basis risk when trying to hedge customized longevity swaps (i.e. the risk that adverse longevity evolution in the insured portfolio is not reflected in the corresponding national population(s) so that the hedge becomes imperfect). Multi-population models provide additional insight about basis risk, but they need to be refined to take into account individual characteristics and their evolution.

Another promising direction are population dynamics models, inspired by ecological models and suitably adapted to human longevity by adding age in the set of traits. Age evolution may either be acknowledged by time-dependent factors or represented by considering physiological age, as in multi-state models. Modeling the entire population enables to incorporate the effect of heterogeneity of birth patterns between socio-economic classes on mortality rates that are observed decades later. They may also allow for postponing mortality improvements due to a temporary or permanent change in the traits distribution, like in the famous case of smoking Danish women (cf. Prescott et al., 1998, and Lindahl-Jacobsen et al., 2016). Some preliminary results have been obtained by Boumezoued et al. (2016), but much more work is needed to better exploit the use of micro-level information in macro models. The two main challenges for population dynamics modeling concern estimation (particularly the lack of parsimony for estimation) and parallelization problems that appear in simulations when individuals may interact in various ways (epidemics, migration impacts on economy and health care systems, etc.). Since individual characteristics are involved, national healthcare databases would be an ideal source of information for estimation purposes. Evidently, however, this brings up ethical issues as well as data privacy problems. 
The complexity of longevity patterns leads to the challenge for actuaries and demographers how to communicate them. One suggestion is to use a set of scenarios, like in climate change studies. Classical scenarios provided by demographers differ quite substantially: Oeppen and Vaupel (2002) popularized the "best practice line approach": in this scenario, life expectancy at birth in the leading country is supposed to continue to increase linearly over time. Other demographers prefer longevity deceleration scenarios: one then continues to observe rectangularization of survival curves due to a kind of biological age limit (Wilmoth and Horiuchi, 1999). Others like de Grey and Rae (2007) believe in a longevity acceleration scenario. Lutz and Samir (2011) evaluate the scientific quality and credibility of the different theories (see also Debonneuil et al., 2015). In general, scenarios should be built using both the above-mentioned models as well as a certain anticipation of societal changes.

Longevity forecast and uncertainty quantification are important for inter-generational issues. One generally expects to pay an appropriate amount, and to get the correspondingly appropriate right benefit from retirement to death. But achieving fairness thanks to risk sharing and redistribution between generations is a complicated issue, due to uncertainty on long term interest rates, demography and feedback effects on both that are difficult to assess. It also leads to questions about rights to vote and the opportunity to share or transfer not only monetary units but also labor power. In many countries, the retirement age has recently been increased or indexed on life expectancy levels. To tackle inter-generational issues, it is important to use the appropriate tools. As an example, for public policy one often uses the old age dependency ratio, which is the number of people aged 65 years and above divided by the number of people aged 20 to 64 . This ratio gives the impression that the situation will be worse in Western Europe than in Eastern Europe in 2030. But as noted by Samir and Lutz (2014), one gets the opposite conclusion using the prospective old age dependency ratio, obtained after replacing 65 by an old-age threshold that corresponds to the age at which residual life expectancy is 15 years. Future longevity improvements, political decisions and labor market participation of seniors are inter-dependent factors, and indicators must be chosen carefully.

Fairness can also be discussed inside a generation. On average, rich men tend to marry late to younger wives, and have children late. They live longer than the average individual because they have better access to healthcare and more assistance from family members, just to name two factors. Should one take into account this heterogeneity for reserving? What about pricing? Should one split or share the risks, or redistribute? The distinction between insurance and social system sometimes becomes a sensitive public policy issue.

\subsection{Impact of societal changes on old-age provision}

The society is changing. Divorce rates have increased, individuals may be married several times and may need to protect several persons with reversionary benefits. Married couples may live in two different areas, while many unmarried couples live together. This makes it more difficult to use marital status for forecasts. There are also changes in the way members of a couple take care of each other at old ages. Family members are on average much more geographically scattered nowadays than they used to be. Long term care is highly institutionalized in the north of Europe, while it is still mostly based on home care in Southern countries. There is a real need for reliable long term care solutions, but policyholders are often 
reluctant to buy long term care insurance. Also, from the insurance industry perspective, finding the adequate price and offering is still a challenge (e.g. lack of dependency tables for nationwide population). Coming back to fairness, one may raise here again a potential gender inequality: on average, women tend to help their husband in their way through their long term affection, while the reciprocal help is absent when they need some after the death of their husband.

\begin{abstract}
"Are we going to live longer?" is a relevant question for pension risk management. Both at the societal level and for insurance companies which sell contracts embedding long term care insurance, a related question is even more important: "are we going to live longer in good health?" Research about this question is vast and builds on demographic studies, medical science studies including cell protection and repairing strategies, and many other fields like economics (for example on the willingness to pay for a reduction of mortality). It also depends on the future behavior of elderly people. Many countries have debates about the end of life and legal rights to a so-called decent end of life. Will persons who have assisted their parents through a painful end of life be eager to terminate their own lives early if they are diagnosed with a comparable disease? Are they now perhaps in this state of mind, but likely to change their perspective when they get there? The answer to this question depends on many factors including the development of religious beliefs, medical costs, social inequalities and public health policy. What if individuals preferred to live a happy life rather than a long life? Since the late eighties, biostatistical research witnessed a shift from statistical survival analysis to (health-related) quality-of-life modelling ((HR)QOL). Coming up with models for time-tilldeath, or time-till-onset of a particular disease or state of invalidity is much easier than designing, for instance, an objective (HR)QOL-index. Similarly, actuarial products which combine components for life and long-term care are not easy to construct even though important from a market point of view.
\end{abstract}

Choices and preferences of individuals will be important not only close to the end of life, but also earlier. Many optional guarantees are embedded in the various pension schemes and life insurance products. Risk management starts at contract design. Even if it is too late for some portfolios, one must reflect about when the choice should be given to the policyholder. For example, if the spouse is about to die, a policyholder is likely to decline the optional reversionary benefit (if allowed by the contract design) and to convert it into a full annuity. Customer rationality is not purely financial. It is also motivated by personal financing needs and other events (e.g. to help a grandchild purchasing the first flat). For sophisticated contracts, this may breed partial surrenders that are not directly related to rationality with respect to financial markets, but not completely independent from them (as it is possibly correlated with interest rates and housing markets). Another important aspect will be the level of trust of customers and the extent to which they appreciate guarantees in the system.

\title{
3.4. Moving away from guarantees?
}

Longevity risk may be partly diversified when one thinks of a very small portfolio (hundreds or thousands of individuals). But at the level of countries, regions or reinsurers, it features a great portion of systematic, undiversifiable risk. It is unclear who is supposed to compensate in case of problems. In some cases, rules or regulators allow companies to go back on promises rather than guarantees (see also Section 5.3). In the US, the pension benefit guarantee program has 
been established for this purpose. In the UK, there is a pension protection fund. In Switzerland, there is a government guarantee. But what is the quality of these guarantees in the presence of systematic risk? As long as no major default has occurred, people tend to believe that it cannot happen. Nevertheless, one needs profitability to benefit from diversification, and profitability remains very uncertain in the future for longevity and long term care risk management.

A concrete source of diversification is nevertheless available: so-called natural hedging of longevity risk with mortality risk is often performed by large insurers and by reinsurers. But the asymmetrical aspect of longevity and mortality risks makes them the main characters of the "tale of two tails": on the one hand, extreme scenarios for longevity risk correspond to longevity improvement acceleration; they correspond to long term risks that materialize more and more over time. On the other hand, extreme mortality events correspond to pandemics, which may decrease life expectancy by 20 years within a year for some generations. Correlation with finance and the economy are also very different: it is hard to understand the effect of longevity acceleration or deceleration on economic variables, but it would correspond to long term, progressive effects. Correlation of pandemic risk with finance is more immediate. During the 2002 SARS epidemics, the GDP went down by $0.5 \%$ on average globally. One can imagine that the effect of a global pandemic on capital markets and on the economy in general would be huge. Besides, climate change and political risks may breed migrations, as well as natural and man-made disasters. This is another source of long term correlation between longevity and economic variables. Migrations and disasters impact longevity, mortality and the economy. Therefore, they should at least be embedded in some scenarios.

\section{Risk management: valuation and solvency}

\subsection{Market consistent valuation}

There is currently no generally accepted definition of market consistency. In fact, wildly varying valuation standards are called market-consistent, which makes a comparison difficult. Solvency II was to be based on a market consistent valuation standard. During the financial crisis, the valuation standard has however been adapted and became internally inconsistent, see for instance, the discussion around illiquidity premiums. Equally, the International Association of Insurance Supervisors (IAIS) aspired to have market consistent, economic valuation standards to be globally implemented. It then defined economic valuation to also include amortized cost, which opens the acceptable valuations that can be used to a wide variety of different approaches.

We here define market consistency as an approach which arrives at a realistic assessment of the cost to produce the liability cash flow. For the purpose of solvency assessment and risk management, it is most important that the cost of the liabilities for the insurer or pension fund is determined. It seems reasonable that the determination of these costs should be based on the specific portfolio and cost structure of the insurer or pension fund. They sell policies which promise a future cash flow to beneficiaries for which they receive premiums. The premiums are used to buy financial instruments whose returns are supposed to meet the (uncertain) future liability cash flows. Since in most cases, financial instruments cannot 
perfectly produce the liability cash flows, insurers and pension funds have to hold capital to buffer any discrepancy between asset returns and actual claims. The cost of holding this capital is an additional cost component that has to be provisioned for.

The market consistent value of liabilities consists of the cost for the replicable part of the claims, expenses and the capital required to buffer the risks that cannot be replicated by financial instruments. Conceptually, the liability cash flow is separated into two components. One component that can be perfectly replicated using financial instruments (in all possible states of the world) and one component that cannot be replicated (the residual). The market consistent value is then the market value of the portfolio of financial instruments that replicate the first component plus a risk margin. The risk margin is defined as the expected cost of holding the capital that has to be held over the lifetime of the insurance liabilities to buffer the risks emanating from the second (non-replicable) component of the liability cash flow.

The risk margin has to be defined consistently with the overall assumption of the market consistent valuation standard. The risk margin depends on both the financial instruments that are used for replication, as well as on the type of replication (static or dynamic) and the definition of capital that has to be held to buffer non-replicable risks. For example, if the chosen financial instruments contain default risk, this risk will influence the amount of capital that needs to be held and therefore has to be taken into account in the risk margin.

The general problem is one that will be experienced by any conceptual framework: sensible concepts can be expected to be "hijacked" in crises, as arguably happened during Solvency II. Reasonable debates over implementation and how one operationalizes the concept of market consistency can become battlegrounds in such times. Hypothetical financial instruments can often be used to replicate liability cash flows, and illiquid financial instruments are often used for replication. The best defense of the general concept of market consistency is to recognize the difficulties in implementation, particularly for long-term debts and for risks that are thinly traded. It might seem odd to defend the concept by pointing out its limitations, but that may protect it from short-term, dogmatic mis-application.

It can be reasonably argued that the transition from Basel I to Basel II unlocked the capital reserves of banks. So for many the transition from Solvency I to Solvency II was an attempt to mimic the same liberation of capital reserves for non-bank financial institutions. Whether these reforms achieved those goals is questionable. But it is important to recognize that the structure and rationale behind the pillars of Solvency II did not reflect the structured thoughts of academics. This is not to say that the "scribblings of academics" always provide a direct link to internal consistency and logic, but just that one should not present Solvency II as if it reflected a reasoned and logically coherent set of principles. For an early warning in the context of Basel II, see, for instance, Danielsson et al. (2001). In effect, one might question whether the fundamental research on market consistency was "ready for prime time" application. Whatever the answer to that question, the basic research that was available at the time did not play a major role in building the edifice of Solvency II.

Another important definitional question concerns the meaning of "valuation." There is necessarily some subjectivity in the valuation of risky prospects, whether it is the subjective 
belief distributions of risks, the selective appeal to "demand-side" or "supply-side" approaches to valuation when markets might be in disequilibrium, or the substitutions and proxies necessitated by the simple lack of directly replicating instruments. Recognizing this subjectivity, again, is perhaps the best way to defend the general principle of marketconsistent valuation, avoiding claims that it is unrealistically objective.

Valuation of liabilities is in general a difficult task: the fundamental market-consistent value is hard to estimate and reflects strong sensitivities to financial variables, in particular the discount curve. In this context, a crucial question, in particular in the present market environment, is: Can one reasonably speak about a risk free discount curve? How can it be determined? We will touch upon this point in Section 5 also.

One particular concern with valuation is that markets for securitizing long-term, longevity risk are generally one-sided. There is lots of demand, but very little supply. The potential for encouraging new instruments in this domain is clear, and the hope is that financial engineering entrepreneurs will arise to fill that gap (see, e.g., Wilson, 2015).

\subsection{Economic and regulatory capital models}

One should distinguish economic capital models from regulatory capital models. Both are concerned with the downside of the distribution of risks a company faces. The first type of model is a tool of managerial accounting, more precisely risk management accounting. The second type of model is focused more narrowly on "ruin" or "run off" as thresholds that must be accounted for statistically, as well as legally in terms of the regulatory environment. Although these models obviously have some features in common, they are motivated by different questions, and the answers they provide can reasonably differ because they have to take into account different constraints.

A particular example is the question of the adequate time horizon for the valuation and risk assessment. In the following, we outline a toy example that focuses on asset valuation and risk assessment. Assume a risk-free discount rate of zero and consider a liability portfolio that pays 100 in two years. These liabilities are matched by a well-diversified asset portfolio consisting of 102 investment grade (BBB) bonds maturing in two years with face value one. Default events are independent. The objective default probability of an individual bond is $0.5 \%$, the recovery rate is $40 \%$, and its current spread is $2 \%$ over risk-free. The absolute spread volatility is $1.4 \%$ per annum. This asset-liability portfolio is admissible on a long-term view: the 99\% expected shortfall of the asset portfolio in two years is less than 2 . Hence the liabilities can be fully met in the worst expected one in one-hundred years loss. Still there exists a capital shortfall of 3.4 today, which is composed of two parts. First, the present value of the asset portfolio is 99.6, which amounts to a capital shortfall of 0.4 . Second, the $99 \%$ expected shortfall of the value of the asset portfolio due to the spread volatility and defaults in one year is 3 . This example shows that holding a well-diversified bond portfolio matching the liabilities at maturity may be admissible on a long-term view, while marking it to market on a one-year time horizon results in a capital shortfall today. There are two reasons for this. First, the liquidation view requires a positive market value of the asset-liability portfolio at any point in time. Second, in the same vein, the bond spread risk on a one-year time horizon is fully capital charged, albeit the bonds may be held to maturity. This raises the question whether regulatory 
capital based on a one-year time horizon is appropriate in view of a long-term asset-liability strategy.

Of course, this example ignores liability risk. But still it raises the issue of a going concern versus a liquidation view or, somewhat equivalently, cash flow solvency versus balance sheet solvency. We believe that this issue has not been adequately solved yet. A typical argument against the liquidation view goes in the direction of insurance liabilities being illiquid so that the insurer does not need to liquidate and may hold illiquid assets. In our opinion, these arguments have never been subject to rigorous analysis. How illiquid are insurance and pension liabilities as opposed to bank deposits? In shock situations there may be an acceleration of liability payments. One example is a pandemic that may affect a life book because significantly more than anticipated people die. Another example is a sudden change of the economic environment due to interest rates jumping up causing huge lapses, similar to a bank run. At the same time the quality of illiquid assets may deteriorate such that the insurer needs to replace them by higher quality assets. This can also be a systematic occurrence where not just one asset class deteriorates. In such a case the insurer would need to liquidate more assets. In summary, it is a pending open issue how to possibly adopt valuation rules that take into account illiquidity of insurance and pension liabilities in view of a long-term asset-liability management.

When do standard measures of risk provide coarse, but useful, approximations to ideal measures? Can the answer to this question take into account the limited ability of different audiences to understand more sophisticated measures? When can a scalar reliably and uniquely characterize a vector? It is sometimes claimed that the risk measure for the solvency capital requirement should be calculated in terms of a risk-neutral (rather than the physical) probability measure, so that risk is measured in terms of value (that is, as the price of the protection we choose not to buy, see Basak and Shapiro, 2011, and Kraft and Steffensen, 2013). One should note, however, that the choice of such a risk-neutral measure will typically be ambiguous. A related concern is the potential for strategic manipulation of risk measures, particularly if they involve reports of complex outputs from internal models.

The idea to define risk capital as the cost of buying protection against default goes back to Merton and Perold (1993). A major problem with this approach is that that protection does not exist in general. To have a number that represents the value of a non-existent instrument does not provide any information on the operational meaning of the number. Saying " $X$ is an amount of capital that when held in bonds reduces the risk of default by this much" has a clear operational meaning and the insurer knows what to do: he holds that amount of capital. However, saying " $X$ is an amount of money that could be used to buy protection ..." does not have any meaning in the absence of that protection. Unless the insurer can and does buy that protection, the number $\mathrm{X}$ will not have any practical meaning. Moreover, if a company could buy this type of protection (an option against default Merton and Perold, 1993), the company would be effectively default-free.

Finally, it cannot be stressed enough how difficult it is to measure operational risk, which can $\mathrm{d}$ warf the risks traditionally studied and measured. A more economic view is compounded by the extreme difficulties faced when analyzing operational risk data. Such data consist of a combination of internal and external expert opinions, and exhibit statistical complexities well 
beyond the standard assumptions needed in order to come up with a reasonable risk measure estimate, be it VaR or ES. Legal risks are one example, reflected in long-standing debates in accounting circles between the recognition or disclosure of contingent liabilities. Reputational risks are not included in solvency tests, particularly when it comes to comparing banks and insurance companies. In any case, capital alone does not suffice to mitigate operational risks (cf. Wilson, 2015, p. 571).

A deep set of questions revolve around communication issues. What is it that we seek to communicate? And who are we communicating it to? Are we communicating to board members, to shareholders, to the public, or to regulatory policymakers? Different audiences are interested in answers to different questions. Shareholders are interested in the return on investment, taking into account some of the risks of illiquidity and bankruptcy. Policymakers and regulators are often concerned solely about the risk of bankruptcy. Board members might be in between. Reflecting the difference between economic capital models and regulatory capital models, one can expect different answers to these questions, implicitly reflecting the loss functions that different stakeholders have. It would be odd if any one measure addressed the needs of all stakeholders.

\section{Role of financial markets}

\subsection{Sustainability of capital-based pension systems}

It is understood that capital-based pension systems are indispensable for modern societies. According to the life cycle savings and investment literature (Bodie, 2002), rational economic agents find it optimal to accumulate a stock of value prior to retirement in order to decumulate that stock during retirement. Old age provision has historically developed from intergenerational (pre-industrial economies) over employer-sponsored (industrial economies) to private capital-based solutions (post-industrial and service-based economies). The latter constitute the present complete solutions provided by insurers and pension firms covering the accumulation and decumulation phases as substitutes for employer- and state-provided solutions. More recently, old age provision has entered a phase of disintermediation. The large volumes accumulated in private, capital-based systems provided by insurers and pension firms represent an attractive target for other competitors. For illustration, in Switzerland in 2014 the assets in the occupational pension scheme ( $2^{\text {nd }}$ pillar) accumulated to estimated 975 billion CHF and in the private pension schemes ( $3^{\text {rd }}$ pillar) to 156 billion CHF [source: Swiss Life Asset Managers]. The global pension fund assets have been estimated 33.9 trillion USD in 2012 [source: PwC Asset Management 2020]. Financial innovation and competitive forces begin to disintermediate complete solutions, bringing alternative products offered at different points in the life cycle value chain to increasingly knowledgeable consumers. This has become possible due to at least five factors:

(i) Higher education and financial literacy, leading to a more informed decision maker. ${ }^{7}$

(ii) Greater labor flexibility and mobility, requiring portable solutions with greater flexibility during the accumulation phase.

\footnotetext{
${ }^{7}$ Still, the average financial literacy is typically limited, cf. Section 2.
} 
(iii) Lower transaction costs and greater availability of savings and investment alternatives, due to digitalization and technological innovation (e.g. computers, telecommunication) supporting better access to financial markets and lower administration costs, and due to financial innovation (e.g. the development of mutual- and managed equity and fixed income funds, ETFs, etc.).

(iv) Level playing field for the various solutions, that is, the availability of a wider range of solutions, leading to lower tax incentives for combined solutions.

(v) Increasing regulation and more transparent accounting rules, leading to more reliable information.

It is understood that the trend towards private solutions, as opposed to employer-sponsored solutions, is irreversible and will continue due to increasing labor mobility, migration, and demographic changes. This is paralleled by an increasing regulatory emphasis moving beyond transparency and focusing on consumer protection and fairness. This will lead to new requirements regarding sales practices, intermediary remuneration, transparency, and aftersales management, which has the potential to fundamentally reshape products and distribution. One can envision a world where technology companies combine access to customers with intelligent automated advice, easy to use administration and account management facilities and an open platform offering modular, transparent and low cost savings, investment and payout alternatives to meet consumers' needs.

In conclusion, simpler, more transparent and cheaper alternative products will emerge with a clearer separation of the savings and annuity phase. From an insurer or pension firm's perspective, the most attractive parts of the life cycle value chain will come under pressure by new, innovative solutions and technologies, leaving behind the capital intensive and lower return activities and services (like classical life insurance products).

\subsection{Transferring insurance risks to the capital markets}

Insurance linked securities are financial instruments whose values are derived from insurance loss events. These include natural catastrophe bonds, extreme mortality securities, but also longevity swaps. Ageing populations growing around the world create the need for longevity risk assumption. On the private side, longevity risk is being taken by insurers and pension firms. The question is: Can longevity risk be assumed more efficiently and more widely by designing some new instruments?

From a general point of view, the volume of funds in the worldwide capital markets also includes capital that is already absorbing longevity risk. In effect, equity investments in insurers and pension firms include that risk. Hence, to a large extent, "transferring risk to the capital markets" really means "transferring risk within the capital markets", usually from a general equity investment vehicle to a specialist investor seeking debt-like instruments. This is distinct from the initial transfer to the capital markets from an individual who for instance seeks a perpetuation of his income by buying an annuity from an insurer or pension firm. 
Within the capital markets there is stratification by product type (debt, equity, etc.) and by risk appetite. Some participants want to shed risk, others want to assume risk. Risk transfer also implies the transfer of return. Premium must be paid to compensate the risk-taker. The premium has to be sufficiently high to entice the risk-taker and sufficiently low to persuade the ceding party that it is worth the cost.

There are at least two motivations for risk transfer:

(i) Shock avoidance. The most important risk transfers take place to cover extreme situations. For example, the announcement of a sudden revelation of a gene therapy that extends life expectancy by three years would be a financial shock to insurers and pension firms and perhaps threaten their viability.

(ii) Risk sharing. Shortage of capital may enforce the transfer of business and associated risk, for instance via some quota share like arrangements.

In transferring risk from one company to another entity there are several levels of consideration, including the following six:

(i) What is form of the risk transfer: debt-like, derivative form, swaps etc.? Who are the agents of the risk transfer, which market/capital are they accessing? Do the agents of these new instruments compete with old transfer agents? Are different licenses needed?

(ii) Who is the natural counterparty to assume the risk? Is there room for speculators to act as risk-takers?

(iii) Is there a desire or intent to create a regular market or is it simply a one-off transaction? If there is desire to create a regular gateway for capital to assume these risks, will there be a secondary market where buyers and sellers can gather the most current information?

(iv) Has there been a recent event that causes some natural movement from equilibrium and hence an immediate demand? Is the current emphasis on longevity driven by its volatility, its trend or simply by regulatory concerns?

(v) Can longevity be modeled? Is there an independent modeler of longevity risk who can assess risk for new investors? Can an index be designed? Will issuers accept basis risk?

(vi) Can longevity risk be justifiably called a new asset class? What is the main argument to persuade new investors to commit to this as a new asset class? What are the enduring arguments for a sustained new market?

As a consequence, the path to success of insurance linked securities has been tortuous rather than smooth, and is still evolving. In particular, the longevity swap market is still an intransparent bilateral market. A generally accepted longevity index is needed. This calls for an independent body of experts on demographics. Potential investors also face the question of how longevity and market risks diversify. There is yet a lot of research needed in this direction. 


\subsection{Asset and liability management: long term perspective}

Quantitative finance solutions towards increased model performance underlying assetliability management and portfolio optimization exist and have to be further developed. Examples include shrinkage methods for robust covariance estimation, which feeds into assetliability portfolio optimization. Another example is to use fundamental corporate data such as earning to price ratio in conjunction with models of financial markets to improve the estimation of asset return parameters.

Can capital markets provide solutions to long-term capital guaranteed (insurance) policies? Here, a capital guarantee means an explicit $100 \%$ guarantee of the invested capital with a AAA-creditworthiness level of the issuer. There are three aspects to this question.

First and foremost, the simple answer is no. In the current ultra-low interest rate environment where one unit of currency today is worth the same value in ten years or even less in some major currencies, there is no possibility to construct capital guaranteed solutions in the standard form where a AAA-rated bond defines the capital guarantee. Other forms of solutions via capital markets by pooling some assets, grouping and slicing them and finally issuing some financial products, also cannot produce the required capital guarantee level in the current market conditions. Hence the question is not whether there is a clever way to use capital markets to create a $100 \%$ capital guarantee product but whether there are feasible and acceptable alternatives to the $100 \%$ guarantee products.

Second, the particular current market environment has revealed some issues with the usage of "capital guarantees". Such guarantees are neither explicitly priced nor made transparent. There is no independent agent which prices the guarantees of different issuers and who makes the different prices transparent. In a period where a binding $100 \%$ capital guarantee is not possible, less restrictive "guarantees" are needed (e.g., a guarantee that holds only with a probability of $\mathrm{x} \%$ ). However, while it is not even clear how to call such a guarantee, the distribution channels are neither trained nor used to advice clients for such types of products and there is little knowledge about how clients respond to such solutions.

Third, one should stop thinking in terms of bonds. When one thinks about a guarantee one immediately calls for a government bond to deliver the guarantee. But the market for long term government bonds is highly illiquid. Are there alternatives to the traditional bond capital guarantee link and if there are any, how are they communicated to the clients? Currently, there exists no asset supplier to long-term guarantees.

About the Swiss Risk and Insurance Forum. The Swiss Risk and Insurance Forum was created in 2014 with the mission to bring together experts from academia, the insurance industry, regulatory bodies and consulting companies to discuss (typically technical) topics that are relevant to the insurance industry. The main objective is to provide a platform on which people from academia can interact with those involved on the more practical side of the insurance industry. This shall facilitate the knowledge transfer in both directions helping enrich the research agendas of the academic institutions and enabling those dealing with 
practical matters to partake in the newest academic developments. The 2015 workshop on old-age provision gathered 36 experts for two days of presentations and discussions.

More information can be found at

http://cgd.swissre.com/events/Swiss_Risk_and_Insurance_Forum.html.

Acknowledgements. We thank Stephan Schreckenberg for suggesting the format of the conference, and for his critical and active support in the creation of the Swiss Risk and Insurance Forum. We also thank all participants for the stimulating and lively discussion. The Swiss Risk and Insurance Forum 2015 received financial support from Deloitte, Swiss Re, Zurich Insurance Group, the Center on Risk Analysis and Risk Governance (CRAG) at EPFL, the ETH Risk Centre and RiskLab, and the Center for Finance and Insurance at the University of Zurich.

List of participants: Aellig Matthias, Swiss Life; Albrecher Hansjörg, University of Lausanne; Antolin Pablo, Organisation for Economic Co-operation and Development (OECD); Babbel David, Wharton School; Binswanger Klemens, Swiss Re; Bommier Antoine, ETHZ; Bütler Monika, University of St. Gallen; Cairns Andrew, Heriot-Watt University; Camara Leopoldo, Swiss Re; Dacorogna Michel, SCOR; Embrechts Paul, ETHZ; Filipović Damir, EPFL and Swiss Finance Institute; Furrer Hansjörg, Swiss Financial Market Supervisory Authority (FINMA); Germann Hansjörg, Zurich Insurance Group; Gersbach Hans, ETHZ; Giger Peter, FINMA; Harrison Glenn, Georgia State University; Janssen Martin, Ecofin and University of Zurich; Junker Lukas, Zurich Insurance Group; Keller Philipp, Deloitte; Koch Pablo, University of Zurich; Lane Morton, Lane Financial LLC; Lindberg Carl, Chalmers University of Technology; Loisel Stephane, Université Lyon 1; Lutz Wolfgang, Vienna Institute of Demography; Mimra Wanda, ETHZ; Moeller Thomas, PFA and University of Copenhagen; Pennanen Teemu, King's College London; Post Thomas, Maastricht University; Raaflaub Patrick, Swiss Re; Schmutz Michael, FINMA and University of Bern; Schreckenberg Stephan, Swiss Re; Steffensen Mogens, University of Copenhagen; Vanini Paolo, Zürcher Kantonalbank; Wagner Joël, University of Lausanne; Wilson Thomas, Allianz

\section{References}

Basak, S. and Shapiro, A. (2001). Value-at-risk-based risk management: optimal policies and asset prices. Review of Financial Studies, 14(2), 371-405.

Bodie, Z. (2002), Life-Cycle Finance in Theory and in Practice. Boston University School of Management Working Paper No. 2002-02. Available at http://ssrn.com/abstract=313619.

Boumezoued, A., El Karoui, N., Loisel, S. (2015) Measuring mortality heterogeneity with multistate models and interval-censored data. Working paper, Université de Lyon 1.

Brüggen, L., Eberhardt, W., Post, T. (2015), Mind the gap: identifying dimensions of heterogeneity between pension plan participants. Working paper, Maastricht University.

Cairns, A., Blake, D., Dowd, K. (2006). A two-factor model for stochastic mortality with parameter uncertainty: theory and calibration. Journal of Risk and Insurance, 73(4), 687-718. 
Cairns, A., Blake, D., Dowd, K., Kessler, A. (2016). Phantoms never die: living with unreliable mortality data. Journal of the Royal Statistical Society, Series A, to appear.

Cutler, D., Deaton, A., Lleras-Muney, A. (2006) The determinants of mortality. Technical report, National Bureau of Economic Research.

Danielsson, J., Embrechts, P., Goodhart, C., Keating, C., Muennich, F., Renault, O., Shin, H. (2001). An Academic Response to Basel II. Financial Markets Group, London School of Economics.

Debonneuil, E., Planchet, F., Loisel, S. (2015). Do actuaries believe in longevity deceleration? Working paper, Université de Lyon 1.

De Grey, A., Rae, M. (2007). Ending aging: The rejuvenation breakthroughs that could reverse human aging in our lifetime. Griffin, New York.

Lazar, D., Denuit, M. (2009). A multivariate time series approach to projected life tables. Applied Stochastic Models in Business and Industry, 25(6), 806-823.

Kraft, H., Steffensen, M. (2013). A dynamic programming approach to constrained portfolios. European Journal of Operations Research, 229, 453-461.

Lee, R., Carter, L. (1992). Modeling and forecasting US mortality. Journal of the American Statistical Association, 87(419), 659-671.

Lindahl-Jacobsen, R., Rau, R., Jeune, B., Canudas-Romo, V., Lenart, A., Christensen, K., Vaupel, J. (2016). Rise, stagnation, and rise of Danish women's life expectancy. Proceedings of the National Academy of Sciences, 113(15), 4015-4020.

Lutz, W., Samir, K. (2011), Global human capital: integrating education and population. Science, 333(6042), 587-592.

Lynch Jr., J., Netemeyer, R., Spiller, S., Zammit, A. (2010). A generalizable scale of propensity to plan: the long and the short of planning for time and for money. The Journal of Consumer Research, 37(1), 108-128.

Merton, R., Perold, A. (1993). Theory of Risk Capital in Financial Firms. Journal of Applied Corporate Finance, 6(3), 1745-6622.

Moog, S., Weisser, V., Raffelhüschen, B. (2014). Altersvorsorge und die Schweizer Generationenbilanz - Lasten in die Zukunft verschoben. Study report, UBS.

Ntamjokouen, A., Haberman, S., Consigli, G. (2014). Modeling multi-population life expectancy: a cointegration approach. Insurance Markets and Companies: Analyses and Actuarial Computations, 5(2), 12-23.

OECD (2012). OECD Roadmap for the good design of defined contribution pension plans. 
OECD (2014). OECD Pensions Outlook 2014.

OECD (2016). Key pension indicators on pension outcomes and pensions. Available at http://www.oecd.org/els/public-pensions/indicators.htm.

Oeppen, J., Vaupel, J. (2002). Broken limits to life expectancy. Science, 296(5570), 1029-1031.

Prescott, E., Osler, M., Hein, H. O., Borch-Johnsen, K., Schnohr, P., Vestbo, J. (1998). Life expectancy in Danish women and men related to smoking habits: smoking may affect women more. Journal of Epidemiology and Community Health, 52(2), 131-132.

Renshaw, A., Haberman, S. (2006). A cohort-based extension to the Lee-Carter model for mortality reduction factors. Insurance: Mathematics and Economics, 38(3), 556-570.

Salhi, Y., Loisel, S. (2011). Longevity basis risk modeling: a co-integration based approach. Technical report, Université Lyon 1.

Samir, K., Lutz, W. (2016). The human core of the shared socioeconomic pathways: Population scenarios by age, sex and level of education for all countries to 2100 . Global Environmental Change, to appear.

Wilmoth, J., Horiuchi, S. (1999). Rectangularization revisited: variability of age at death within human populations. Demography 36(4), 475-495.

Wilson, T. (2015) Value and Capital Management. A Handbook for the Finance and Risk Functions of Financial Institutions. Wiley, Chichester. 